\title{
Pain Assessment during Gnathological Treatment of Temporomandibular Myofascial Pain through Mandibular Repositioning Splints Designed after a Posture-Stabilometric Evaluation
}

\author{
Michele D'Attilio $^{1, *(\mathbb{D}}$, Federica Migliore ${ }^{1} \mathbb{D}$, Francesco Moscagiuri ${ }^{1}$ and Francesco Caroccia ${ }^{1,2} \mathbb{D}$ \\ 1 Department of Innovative Technologies in Medicine \& Dentistry, University “G. d'Annunzio" Chieti-Pescara, \\ 66100 Chieti, Italy; federicamigliore925@gmail.com (F.M.); francesco.moscagiuri@unich.it (F.M.); \\ Francesco.caroccia@unifi.it (F.C.) \\ 2 Department of Surgery and Translational Medicine, University of Florence, 50127 Firenze, Italy \\ * Correspondence: michele.dattilio@unich.it; Tel.: +39-335-7489425
}

check for updates

Citation: D'Attilio, M.; Migliore, F.; Moscagiuri, F.; Caroccia, F. Pain Assessment during Gnathological Treatment of Temporomandibular Myofascial Pain through Mandibular Repositioning Splints Designed after a Posture-Stabilometric Evaluation. Appl. Sci. 2021, 11, 8303. https:// doi.org/10.3390/app11188303

Academic Editor: Mitsuru Motoyoshi

Received: 21 July 2021

Accepted: 4 September 2021

Published: 7 September 2021

Publisher's Note: MDPI stays neutral with regard to jurisdictional claims in published maps and institutional affiliations.

Copyright: (c) 2021 by the authors. Licensee MDPI, Basel, Switzerland. This article is an open access article distributed under the terms and conditions of the Creative Commons Attribution (CC BY) license (https:/ / creativecommons.org/licenses/by/ $4.0 /)$.

\begin{abstract}
The aim of the study is to evaluate the effectiveness of two complementary mandibular repositioning splints (SVED and MORA) designed after a preliminary patients' posture-stabilometric evaluation in treatment for temporomandibular myofascial pain (TMP) using the Pain-Intensity Numeric Rating Scale (PI-NRS) assessment. Eighty-six consecutive sportive non-agonistic subjects with TMP were randomly divided in two groups. Forty-two wear mandibular repositioning splints designed by a posture-stabilometric evaluation, thus constituting the test group. The other 44 subjects were not subjected to any treatment, thus represented the control group. To record pain intensity, subjects in both groups were asked to fill in a PI-NRS which ranged from 0 (no pain) to 10 (worst imaginable pain). In the test group, PI-NRS was assessed three times: before starting therapy (t0), after 4 months ( $\mathrm{t} 1$ ) and after 8 months (t2) of treatment. Instead, in the control group PI-NRS was recorded during the first visit ( $\mathrm{t} 0$ ) and after 8 months ( $\mathrm{t} 2)$. The Friedman test showed a statistically significant decrease in PI-NRS mean scores after 4 (t1) and 8 (t2) months from the start of the gnathological therapy with mandibular repositioning splints, $(p<0.001)$ in test group. There is enough evidence to assess that occlusal splint therapy for mandibular repositioning (MORA and SVED) designed through a posture-stabilometric evaluation could be considered in the treatment of temporomandibular myofascial pain.
\end{abstract}

Keywords: temporomandibular disorders; occlusal therapy; posture; myofascial pain; personalized medicine

\section{Introduction}

Temporomandibular disorders (TMDs) are a group of neuromuscular and musculoskeletal functional disorders of the masticatory system which include the masticatory musculature, the temporomandibular joints (TMJs) and the associated structures [1]. TMDs are highly prevalent, and they represent the second most common cause of orofacial pain [2], although surveys assessed a lack of knowledge among dentists on their symptoms and treatments [3,4]. One of the most common TMDs' clinical manifestations is temporomandibular myofascial pain (TMP) [5], which causes pain in orofacial region, and consequently disability and deterioration of quality of life. This is a highly significant health problem and about $85 \%$ of the general population experience at least one episode during their lifetime, while the estimated overall prevalence is $\sim 46 \%$ [6]. Myofascial pain is a collection of sensory, motor, and autonomic symptoms that include local and referred pain, decreased range of motion, and weakness; and its main cause is believed to be attributable to myofascial trigger points (MTrPs) [7,8]. Indeed, for many clinicians and researchers, one or more MTrPs is necessary to ensure the diagnosis of myofascial pain. MTrPs are 
hypersensitive, palpable areas, made of several contracted motor unities, located in a taut skeletal muscle band [9]. Regarding the orofacial region, MTrPs could be frequently observed in masticatory muscles (i.e., temporal, masseter, lateral pterygoid, medial pterygoid) and neck muscle (i.e., sternocleidomastoid muscle). Investigations about myogenous and internal disorders of TMJ could be developed using the Research Diagnostic Criteria for Temporomandibular Disorders (DC/TMD) to allow standardization and replication of the research on TMDs [10].

Several therapeutic approaches have been proposed to treat temporomandibular MP. Pharmacological treatment, psychological support, physiotherapy, and occlusal therapy are commonly used alone or in association to treat temporomandibular MP [11-13]. Noninvasive approaches such as occlusal splints are the most commonly used because of their safety and convenience [14]. Splints are removable appliances, usually made of acrylic polymer with steel clasps or linkages that fit over the teeth of either the mandible or the maxilla. Several designs and treatment protocols using occlusal splints have been described in the literature [15]; nevertheless, a low number of randomized controlled trials is available [16] and a valid evidence-based treatment strategy is still debated [16]. The aim of the occlusal splint therapy is to obtain a repositioning of the jaw able to improve muscular comfort and an enhancement in the articular disk relationship with the mandibular condyle [17]. Some studies suggest an occlusal therapy where the jaw is pushed into a more forward position [18], but it should be ideally reoriented in the position which ensures the best comfort for the masticatory muscles and TMJs, as well as the best postural assessment of the whole body. The hypothesis is that an occlusal splint should be personalized on the body postural balance and at the same time able to guide the mandible in a spatial position ensuring both orofacial muscle pain reduction and overall body postural comfort. The relation between body posture and dental occlusion is still debated in the literature [19]. Nevertheless, postural differences between subjects with TMDs and healthy subjects have been observed [20].

The effectiveness of these personalized splint therapy can be assessed by observing changes in self-reported chronic pain intensity [17] through a pain intensity numeric rating scale (PI-NRS) [21].

The aim of this study was to evaluate the effectiveness of two complementary mandibular repositioning splints designed after a posture-stabilometric evaluation, thus obtaining a personalized jaw-repositioning splint that could promote temporomandibular myofascial pain reduction in head and neck districts according to PI-NRS during an 8-month follow-up.

\section{Materials and Methods}

\subsection{Patient Selection}

The sample of this study consisted of 102 consecutive gnathological subjects ( 23 men/ 79 women) aged between 16 and 77 years (44.4 \pm 6.9 years on the average) who had been referred to the Department of Innovative Technologies in Medicine and Dentistry, University of Chieti-Pescara, Chieti, Italy, for diagnosis and treatment of TMD-related facial pain during the time interval from February 2017 to February 2020. The study was conducted in observance of the Helsinki Declaration (revised version of Tokyo in 2004) and Good Clinical Practice Guidelines. All patients were informed about the purpose of the study and were required to give written, informed consent before enrolment.

The following inclusion criteria were used for the enrolment: (i) patients with clinical features fulfilling the DC/TMD [10] of local myalgia, myofascial pain with spreading and myofascial pain with referral; (ii) absence of long-term illnesses that may affect TMJs or the masticatory muscles (i.e., rheumatoid arthritis); (iii) absence of previous treatment for TMD; (iv) no vestibular apparatus alteration or history of vertigo caused by central nervous disease; (v) absence of neuropathic pain, generalized pain (e.g., fibromyalgia), neurovascular headache (e.g., cluster headache or migraine), or any psychiatric disorder. Moreover, the participants did not undergo any dental restoration during the whole period 
of the study, hence preventing any alteration of occlusal surfaces of the teeth. All patients underwent a clinical gnathological visit to assess the DC/TMD [10]. After collecting a complete medical and dental patient history including a description of the pain in head and neck area (type, frequency, and intensity), a clinical evaluation was performed. The visit included maximum comfortable jaw opening measurement, assessment of clicking, tenderness at rest and during jaw eccentric movements, deviation during opening and closing mouth movements. Tenderness of the extraoral and intraoral masticatory muscles and neck muscles was evaluated by manual palpation. Eighty-sixsubjects (15 men and 71 women) of the initially 102 fulfilled our inclusion criteria and were randomly divided in two groups: 42 (10 men and 32 women) constituted the test group wearing mandibular repositioning splints, while the other 44 ( 5 men and 39 women) constituted the nontreatment control group.

\subsection{Mandibular Repositioning Waxes Registration}

One week after the first visit, in the test group, three hard waxes for mandibular repositioning were recorded by the same expert doctor (M.D.). Patients were guided to bite a wax construction bite made up of two external layers of hard pink wax (Beauty Pink, Miltex, York, Commonwealth of Pennsylvania, USA) covering three layers of soft pink wax (Tenatex Red, Kemdent, Swindon, UK) (Figure 1). The wax construction bite was positioned just behind the superior cusps and then the jaw was guided to bite on it.

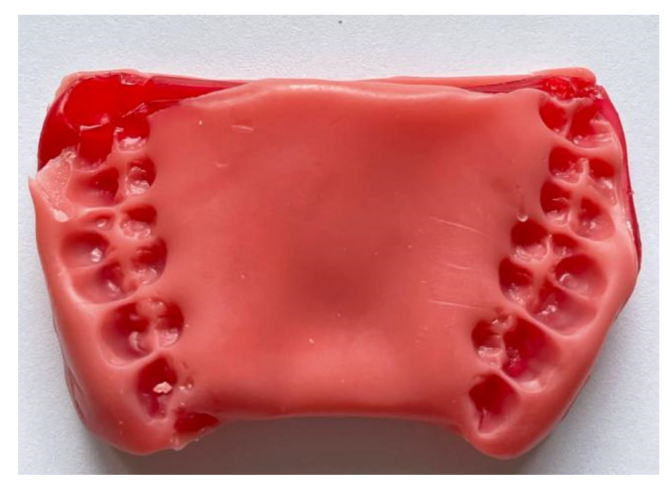

(a)

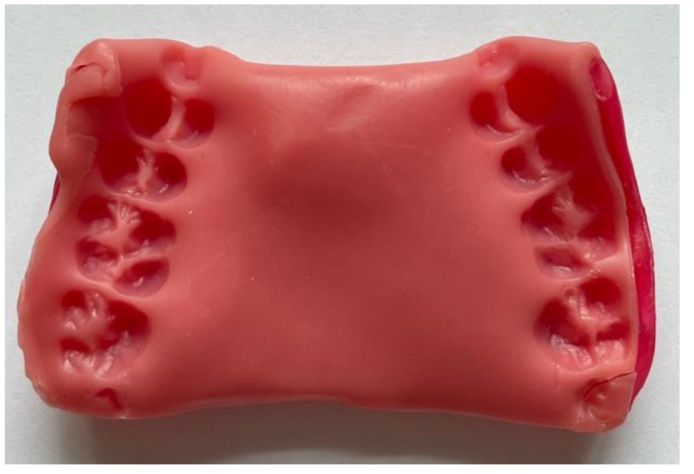

(b)

Figure 1. Wax registration for mandibular repositioning. (a) Lower side; (b) Upper side.

Three waxes registrations were performed: (i) the first wax advancing the jaw and aligning maxillary and mandibular labial frenula; (ii) the second one advancing the jaw without aligning labial frenula (this wax was registered only if a labial frenula discrepancy was present); (iii) the last one in a minimal vertical occlusal dimension increase. In the first two waxes, the jaw was advanced until it reached an ideal vertical and sagittal inter-incisal relation according to Björk [22] with $2 \mathrm{~mm}$ of overjet and overbite. In the third wax, vertical occlusal dimension was increased until the first dental contact was reached.

\subsection{Posture-Stabilometric Examination}

Each repositioning wax was evaluated by a posture-stabilometric examination in order to record the new body postural assessment after mandibular repositioning and choose which wax assured the most comfortable body posture. A vertical force platform (Lizard; Lemax s.r.l., Como, Italy) and its software (Lizard v 3.0; Lemax s.r.l., Como, Italy) were used for the posture-stabilometric evaluation. Each subject was placed on the platform and was asked to maintain the most stable and relaxed body posture with their arm resting along the body. Natural head position was reached asking the subject to gaze a reference point painted on the wall $90 \mathrm{~cm}$ away and corresponding with the central axis of the platform.

To eliminate, or highly reduce, subjectivity in the patient positioning, an operator guided patient's feet direction on the platform using the guidance lines plot on the platform 
and moreover a custom-made tool was realized, giving an exact projection of the lateral malleolus center on the platform (Figure 2). All subjects were asked to avoid any physical stress, alcohol, coffee, and stimulating substances, for at least $24 \mathrm{~h}$ before the test. The said test was performed in a quiet room. The posture-stabilometric evaluation was firstly performed in basal conditions, i.e.,:

1. Rest position/opened eyes: slightly separated teeth and masticatory muscles in a relaxed non-contracted condition, with open eyes.

2. Rest position/closed eyes: slightly separated teeth and masticatory muscles in a relaxed non-contracted condition, with closed eyes.

3. Maximum Intercuspidation/opened eyes: reaching the maximum intercuspidation between the teeth and maintaining opened eyes.

4. Maximum Intercuspidation/closed eyes: reaching the maximum intercuspidation between the teeth and maintaining closed eyes.

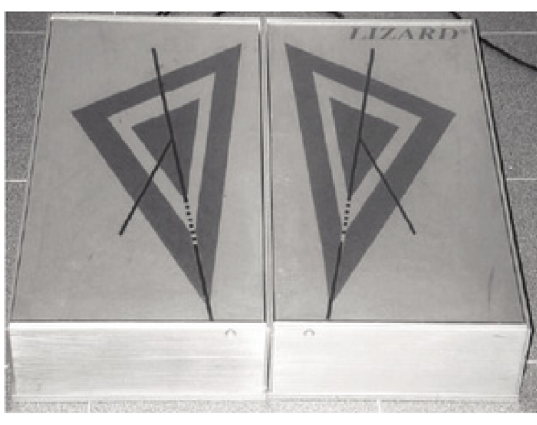

(a)

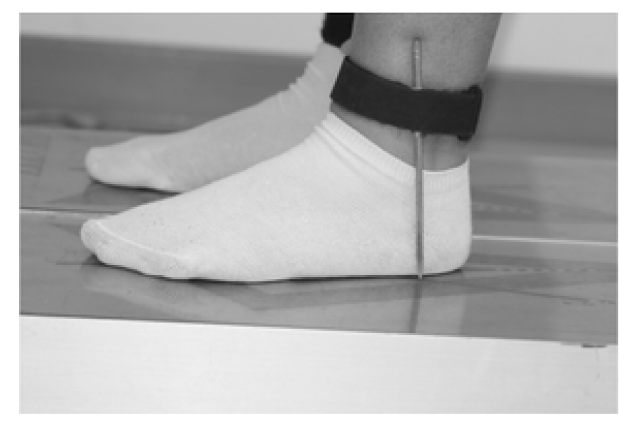

(b)

Figure 2. (a) Posture-stabilometric vertical force platform (Lizard; Lemax s.r.l., Como, Italy); (b) a custom tool for correct positioning of the subject on the platform.

Finally, recordings were performed while the subject was wearing sequentially the two or three mandibular repositioning waxes with open eyes. Each recording lasted $51.2 \mathrm{~s}$ and an operator checked the patient's position on the platform between each recording.

The same expert operator evaluated the results of posture-stabilometric examination. Any change in the postural arrangement was evaluated comparing basal conditions and the two or three registrations with mandibular repositioning waxes. The following parameters were considered to assess the postural arrangement changes: the position of the center of mass, the distribution of the weight on the feet area, and the torsion angles of the body axis regarding the Cartesian axes [23,24]. The mandibular repositioning wax which showed the best postural arrangement according to these parameters were chosen as the reference mandibular positioning in the splint construction.

\subsection{Treatment Procedures}

Two types of splints in a complementary way were used for the splint therapy in the test group: a Mandibular Anterior Repositioning Splint (MORA) [25] during the daytime and a Sagittal Vertical Extrusion Device (SVED) [26] during the night. Splints were designed as described by Tecco et al. [17] and using the wax registration that showed the best improvement of the postural arrangement after jaw repositioning as a reference. All subjects were asked to wear the SVED all night and the MORA the whole day, except during meals.

\subsection{Pain Intensity Registration}

All patients were asked to fill in a PI-NRS which ranged from 0 (no pain) to 10 (worst imaginable pain), in order to record pain intensity. Each subject in both groups (test group and control group) was monitored from the start of the treatment for a total period of eight months. In the test group PI-NRS was assessed three times: before starting therapy (t0), 
after 4 months (t1) and after 8 months (t2) of treatment. Instead, in control group PI-NRS was recorded during the first visit ( $\mathrm{t} 0$ ) and after 8 months ( $\mathrm{t} 2$ ).

The reliability and validity of self-reported measures for assessing pain intensity outcomes have already been demonstrated in the literature [27]. The NRS mostly resulted to be a well-understood measure with an acceptable reliability for pain evaluation in TMD patients [28] without differences in age [29] or gender [30]. The NRS is self-completed by each patient, which is asked to place a circle on the numeric scale at the point that represents his pain intensity. The NRS is easy to administer and score [31], less than one minute is requested to complete it and with minimal language translation difficulties supporting its use across cultures and languages [32]. Unlike other pain-assessment scales, NRS can be administered verbally (therefore also by telephone) or graphically [33].

\subsection{Statistical Analysis}

Statistical analysis was performed using SPSS Statistics for Data Analysis v26. The Shapiro-Wilk normality test was applied. Since data were not normally distributed $(p<0.05)$, a non-parametric test, the Friedman test, was used for the statistical analysis of variance.

\section{Results}

The mean and median values of PI-NRS in the test group at $\mathrm{t} 0, \mathrm{t} 1$ and $\mathrm{t} 2$ are shown in Table 1. In the test group, the intensity of myofascial pain showed a clear improvement (Table 1): the Friedman test showed a statistically significant decrease in PI-NRS mean scores after 4 (t1) and 8 (t2) months from the start of gnathological therapy with mandibular repositioning splints $(p<0.001)$.

Table 1. Mean and Median of Group Test (42 subjects) at $\mathrm{t} 0, \mathrm{t} 1$ (4 months) and $\mathrm{t} 2$ (8 months).

\begin{tabular}{cccc}
\hline PI-NRS & Mean \pm SD & Median & $p$-Value ${ }^{\text {a }}$ \\
\hline t0 & $6.45 \pm 2.03$ & 6.5 & \\
t1 & $4.48 \pm 1.73$ & 4 & \\
t2 & $2.86 \pm 2.12$ & 2.5 & $p<0.01$ \\
\hline
\end{tabular}

Legend: SD, standard deviation; ${ }^{\text {a }}$ Friedman test.

The mean and median values of PI-NRS in the control group at baseline (t0) and after 8 months (t2) are shown in Table 2. No statistically significant result was achieved with the Friedman test, pointing out the permanence or even the worsening of MP symptoms: the average PI-NRS score did not change in non-treated group, or it even resulted to be slightly increased between the first visit ( $\mathrm{t} 0$ ) and after 8 months ( $\mathrm{t} 2)$.

Table 2. Mean and Median of Group Control (44 subjects) at t0 and t2 (8 months).

\begin{tabular}{cccc}
\hline PI-NRS & Mean \pm SD & Median & $p$-Value ${ }^{\text {a }}$ \\
\hline t0 & $6.71 \pm 1.98$ & 7 & \\
t2 & $7.21 \pm 1.73$ & 7 & $p>0.01$ \\
\hline
\end{tabular}

Legend: SD: standard deviation; ${ }^{\text {a }}$ Friedman test.

\section{Discussion}

Myofascial pain is the most common TMD and its etiology is multifactorial. Several therapies and appliances have been developed to try to diagnose it and relieve the associated symptoms [34,35]. Reversible treatments should be preferred to invasive procedures (i.e., occlusal adjustment, through selective grinding of the tooth surfaces) for the rehabilitation of patients with myofascial disease, and generally for TMD [14,36]. Among the successful conservative therapies, occlusal splint therapy has been demonstrated to be effective in the management of pain in patients with TMD [17]. The aim of occlusal 
splint therapy is to establish neuromuscular harmony in the masticatory system by jaw repositioning and to create a mechanical disadvantage for parafunctional forces trough removable appliances [37]. In this study, we evaluated the effectiveness of splint therapy in determining a reduction in myofascial pain, using two anterior repositioning splints in a complementary way (MORA, during daytime, and SVED during the night). The splints design was based on a posture-stabilometric evaluation to find out if a mandibular repositioning could both improve the postural arrangement of the body and reduce myofascial pain in the orofacial region. The possibility that mandibular repositioning could affect body posture has been previously investigated and the aim of our study to obtain a personalized splint is literature-based [38].

In their randomized clinical trial, Sakaguchi et al. [39] demonstrated a reciprocal influence between mandibular position and body posture observing that experimental changes in one of the two system consequently affect the other one. The postural system including both body and head posture is narrowly regulated by a sophisticated information network in which mandibular joint and muscles proprioceptors and periodontal ligament mechanoreceptors are of primary importance through the trigeminal nerve [40]. TMDs typically affect these trigeminal afferences and proprioception mechanisms. This could provoke, with a descending action, an unbalance of the whole postural muscles chains and finally posture alterations. Since occlusal therapy could induce a re-equilibrium of masticatory muscles, this re-equilibrium could influence, with a descending action, the whole body postural muscles, resulting in an improved posture [41].

Mandibular position which allows the best bilateral occlusal contact and ideally overbite and overjet results in reducing disharmony between muscle systems of the right and left sides, regarding both masticatory and neck muscles, such as sternocleidomastoid [39,42,43]. Bilateral disharmonies of the neuromuscular system may lead to the instability of the head position and consequently body posture, but at the same time causing MP.

In this study, PI-NRS scores for pain showed significant improvement throughout all study intervals in the group treated with MORE and SVED splints, while no pain score reduction or even increase was observed in control group without any treatment for 8 months, confirming the reliability of the treatment and the absence of a spontaneous correction of the symptoms. It should be also noted that initial PI-NRS average scores are similar in both test group $(\mathrm{t} 0=6.45 \pm 2.03)$ and non-treated group $(\mathrm{t} 0=6.71 \pm 1.98)$. Our results agree with literature evidence about TMD-related orofacial pain treatment trough occlusal splints even if they have been personalized through a posture-stabilometric examination. In two studies, Tecco et al. $[17,18]$ demonstrated the effectiveness of occlusal splints in TMD-related orofacial pain reduction. One [17] of these two studies used the same MORE and SVED appliances, and this is an evidence of the reliability of these splints, even if designed through a body postural analysis. According to the meta-analysis by Zhang et al. (2016) [44], splint therapy reduced pain intensity measured with the visual analogue scale (VAS) in patients with TMD without specific description (TMDSD) and reduced the frequency of painful episodes in patients with TMJ clicking. In our study, the test group showed a progressive decrease in pain intensity across the $\mathrm{t} 1(4.48 \pm 1.73)$ and t2 $(2.86 \pm 2.12)$ recordings. These results suggest that improvements are progressive and related to the time of the patient's wearing of the splint, in accordance with Milani et al. [45], reporting that the effect of occlusal splints requires a period of muscular adaptation.

\section{Limitation}

This study presents some limitations. The absence of blinding both in patients and clinicians and the absence of a control group treated with standard mandibular repositioning splints indicate the necessity of future RCT overcoming these limitations to assess the effectiveness of the posture stabilometric splint design. Two pain assessment points during eight months of treatment could be poorly for a continuous and fluctuating phenomenon such as pain and the pain assessment should be also flanked by a functional analysis. 


\section{Conclusions}

Based on our results, it is possible to conclude that there is enough evidence to assess that occlusal splint therapy for mandibular repositioning (MORA and SVED) designed after a posture-stabilometric evaluation could be considered to treat temporomandibular myofascial pain. Occlusal splint therapy resulted to be effective in reducing pain severity over an 8-month follow-up. Moreover, the study pointed out the useful purpose of a personalized mandibular repositioning to improve both masticatory muscles comfort and body posture.

Author Contributions: Conceptualization, M.D. and F.C.; methodology, M.D., F.M. (Francesco Moscagiuri) and F.C.; software, F.M. (Federica Migliore); validation, M.D., F.M. (Francesco Moscagiuri) and F.C.; formal analysis, M.D., F.M. (Francesco Moscagiuri) and F.C.; investigation, F.M. (Federica Migliore); data curation, F.M. (Federica Migliore); writing—original draft preparation, F.M. (Federica Migliore); writing—review and editing, F.C.; visualization, M.D., F.M. (Francesco Moscagiuri) and F.C.; supervision, M.D. All authors have read and agreed to the published version of the manuscript.

Funding: This research received no external funding.

Institutional Review Board Statement: The study was conducted according to the guidelines of the Declaration of Helsinki, and approved by the Institutional Review Board (or Ethics Committee) of Università degli Studi “G.d'Annunzio" Chieti-Pescara (protocol code 1858, 11 July 2019 approved on 6 February 2020).

Informed Consent Statement: Informed consent was obtained from all subjects involved in the study.

Data Availability Statement: The data presented in this study are available on request from the corresponding author.

Acknowledgments: The authors thank Erica Di Maria who provided language assistance.

Conflicts of Interest: The authors declare no conflict of interest.

\section{References}

1. Gauer, R.L.; Semidey, M.J. Diagnosis and Treatment of temporomandibular disorders. Am. Fam. Physician 2015, 15, 378-386.

2. Manfredini, D.; Guarda-Nardini, L.; Winocur, E.; Piccotti, F.; Ahlberg, J.; Lobbezoo, F. Research diagnostic criteria for temporomandibular disorders: A systematic review of axis I epidemiologic findings. Oral Surg. Oral Med. Oral Pathol. Oral Radiol. Endod. 2011, 112, 453-462. [CrossRef]

3. López-Frías, F.J.; Gil-Flores, J.; Bonilla-Represa, V.; Ábalos-Labruzzi, C.; Herrera-Martinez, M. Knowledge and management of temporomandibular joint disorders by general dentists in Spain. J. Clin. Exp. Dent. 2019, 11, e680-e685. [CrossRef]

4. Mozhdeh, M.; Caroccia, F.; Moscagiuri, F.; Festa, F.; D'Attilio, M. Evaluation of Knowledge among Dentists on Symptoms and Treatments of Temporomandibular Disorders in Italy. Int. J. Environ. Res. Public Health 2020, 17, 8760. [CrossRef]

5. Reiter, S.; Goldsmith, C.; Emodi-Perlman, A.; Friedman-Rubin, P.; Winocur, E. Masticatory muscle disorders diagnostic criteria: The American Academy of Orofacial Pain versus the research diagnostic criteria/temporomandibular disorders. J. Oral Rehabil. 2012, 39, 941-947. [CrossRef] [PubMed]

6. Simons, D.G. Clinical and etiological update of myofascial pain from trigger points. J. Musculoskelet. Pain 1996, 4, 93-121. [CrossRef]

7. Fricton, J.R.; Kroening, R.; Haley, D.; Siegert, R. Myofascial pain syndrome of the head and neck: A review of clinical characteristics of 164 patients. Oral Surg. Oral Med. Oral Pathol. 1985, 60, 615-623. [CrossRef]

8. Simons, D.G. Review of enigmatic MTrPs as a common cause of enigmatic musculoskeletal pain and dysfunction. J. Electromyogr. Kinesiol. 2004, 14, 95-107. [CrossRef]

9. Simons, D.G.; Travell, J.G.; Simons, L.S. Travell E Simons' Myofascial Pain and Dysfunction: The Trigger Point Manual, 2nd ed.; Williams \& Wilkins: Baltimore, MD, USA, 1999; Volume 1.

10. Schiffman, E.; Ohrbach, R.; Truelove, E.; Look, J.; Anderson, G.; Goulet, J.P.; List, T.; Svensson, P.; Gonzalez, Y.; Lobbezoo, F.; et al. Diagnostic Criteria for Temporomandibular Disorders (DC/TMD) for Clinical and Research Applications: Recommendations of the International RDC/TMD Consortium Network* and Orofacial Pain Special Interest Group. J. Oral Facial Pain Headache 2014, 28, 6-27. Available online: https:// pubmed.ncbi.nlm.nih.gov/24482784/ (accessed on 4 March 2021). [CrossRef] [PubMed]

11. de Melo, L.A.; Bezerra de Medeiros, A.K.; Campos, M.F.T.P.; Bastos Machado de Resende, C.M.; Barbosa, G.A.S.; de Almeida, E.O. Manual Therapy in the Treatment of Myofascial Pain Related to Temporomandibular Disorders: A Systematic Review. J. Oral Facial Pain Headache 2020, 34, 141-148. [CrossRef] 
12. Machado, E.; Machado, P.; Wandscher, V.F.; Marchionatti, A.M.E.; Zanatta, F.B.; Kaizer, O.B. A systematic review of different substance injection and dry needling for treatment of temporomandibular myofascial pain. Int. J. Oral Maxillofac. Surg. 2018, 47, 1420-1432. [CrossRef] [PubMed]

13. Roldán-Barraza, C.; Janko, S.; Villanueva, J.; Araya, I.; Lauer, H.C. A systematic review and meta-analysis of usual treatment versus psychosocial interventions in the treatment of myofascial temporomandibular disorder pain. J. Oral Facial Pain Headache 2014, 28, 205-222. [CrossRef]

14. Liu, F.; Steinkeler, A. Epidemiology, diagnosis, and treatment of temporomandibular disorders. Dent. Clin. N. Am. 2013, 57, 465-479. [CrossRef]

15. Wieckiewicz, M.; Boening, K.; Wiland, P.; Shiau, Y.Y.; Paradowska-Stolarz, A. Reported concepts for the treatment modalities and pain management of temporomandibular disorders. J. Headache Pain 2015, 16, 106. [CrossRef]

16. Rajapakse, S.; Ahmed, N.; Sidebottom, A.J. Current thinking about the management of dysfunction of the temporomandibular joint: A review. Br. J. Oral Maxillofac. Surg. 2017, 55, 351-356. [CrossRef]

17. Tecco, S.; Caputi, S.; Teté, S.; Orsini, G.; Festa, F. Intra-articular and muscle symptoms and subjective relief during TMJ internal derangement treatment with maxillary anterior repositioning splint or SVED and MORA splints: A comparison with untreated control subjects. Cranio 2006, 24, 119-129. [CrossRef]

18. Tecco, S.; Festa, F.; Salini, V.; Epifania, E.; D'Attilio, M. Treatment of joint pain and joint noises associated with a recent TMJ internal derangement: A comparison of an anterior repositioning splint, a full-arch maxillary stabilization splint, and an untreated control group. Cranio 2004, 22, 209-219. [CrossRef]

19. Julià-Sánchez, S.; Álvarez-Herms, J.; Burtscher, M. Dental occlusion and body balance: A question of environmental constraints? J. Oral Rehabil. 2019, 46, 388-397. [CrossRef]

20. Nota, A.; Tecco, S.; Ehsani, S.; Padulo, J.; Baldini, A. Postural stability in subjects with temporomandibular disorders and healthy controls: A comparative assessment. J. Electromyogr. Kinesiol. 2017, 37, 21-24. [CrossRef]

21. Farrar, J.T.; Young, J.P., Jr.; LaMoreaux, L.; Werth, J.L.; Poole, M.R. Clinical importance of changes in chronic pain intensity measured on an 11-point numerical pain rating scale. Pain 2001, 94, 149-158. [CrossRef]

22. Björk, A. Variability and age changes in overjet and overbite. Am. J. Orthod. 1953, 39, 779-801. [CrossRef]

23. D'Attilio, M.; Bondi, D.; Castellani, M.; Verratti, V.; Pietrangelo, T. Sports performance adaptations through occlusal splint: Case reports of triathlon athletes. Cranio 2021, 1-9. [CrossRef]

24. Nagymáté, G.; Orlovits, Z.; Kiss, R.M. Reliability analysis of a sensitive and independent stabilometry parameter set. PLoS ONE 2018, 13, e0195995. [CrossRef]

25. Pertes, R.A. Updating the mandibular orthopedic repositioning appliance (MORA). J. Craniomandib. Pract. 1987, 5, 351-356. [CrossRef]

26. Farha, K.F. SVED. Cranio Clin. Int. 1991, 1, 123-141.

27. Dworkin, R.H.; Turk, D.C.; Farrar, J.T.; Haythornthwaite, J.A.; Jensen, M.P.; Katz, N.P.; Kerns, R.D.; Stucki, G.; Allen, R.R.; Bellamy, N.; et al. Core outcome measures for chronic pain clinical trials: IMMPACT recommendations. Pain 2005, 113, 9-19. [CrossRef]

28. Conti, P.C.R.; De Azevedo, L.R.; De Souza, N.V.W.; Ferreira, F.V. Pain measurement in TMD patients: Evaluation of precision and sensitivity of different scales. J. Oral Rehabil. 2001, 28, 534-539. [CrossRef]

29. Karibe, H.; Goddard, G.; Shimazu, K.; Kato, Y.; Warita-Naoi, S.; Kawakami, T. Comparison of self-reported pain intensity, sleeping difficulty, and treatment outcomes of patients with myofascial temporomandibular disorders by age group: A prospective outcome study. BMC Musculoskelet. Disord. 2014, 15, 423. [CrossRef]

30. Goddard, G.; Karibe, H.; McNeill, C. Reproducibility of visual analog scale (VAS) pain scores to mechanical pressure. Cranio 2004, 22, 250-256. [CrossRef]

31. Jensen, M.P.; Karoly, P.; O’Riordan, E.F.; Bland, F., Jr.; Burns, R.S. The subjective experience of acute pain. Clin. J. Pain 1989, 5, 153-159. [CrossRef]

32. Langley, G.B.; Sheppeard, H. The visual analogue scale: Its use in pain measurement. Rheumatol. Int. 1985, 5, 145-148. [CrossRef] [PubMed]

33. Jensen, M.P.; Karoly, P.; Braver, S. The measurement of clinical pain intensity: A comparison of six methods. Pain 1986, 27, 117-126. [CrossRef]

34. Caroccia, F.; Raimondi, L.; Moscagiuri, F.; D’Attilio, M. Stimulation of Myofascial Trigger Points in the Sternocleidomastoid Evokes Facial Thermal Response Correlated with the Referred Pain. Appl. Sci. 2021, 11, 6510. [CrossRef]

35. D'Attilio, M.; Di Carlo, B.; Caroccia, F.; Moscagiuri, F.; d'Angelo, D.M.; Chiarelli, F.; Festa, F.; Breda, L. Clinical and Instrumental TMJ Evaluation in Children and Adolescents with Juvenile Idiopathic Arthritis: A Case-Control Study. Appl. Sci. 2021, 11, 5380. [CrossRef]

36. Zhang, S.H.; He, K.X.; Lin, C.J.; Liu, X.D.; Wu, L.; Chen, J.; Rausch-Fan, X. Efficacy of occlusal splints in the treatment of temporomandibular disorders: A systematic review of randomized controlled trials. Acta Odontol. Scand. 2020, 78, 580-589. [CrossRef]

37. Dylina, T.J. A common-sense approach to splint therapy. J. Prosthet. Dent. 2001, 86, 539-545. [CrossRef]

38. Saggini, R.; Anastasi, G.P.; Battilomo, S.; Latessa, P.M.; Costanzo, G.; Di Carlo, F.; Festa, F.; Giardinelli, G.; Macrì, F.; Mastropasqua, L.; et al. Consensus paper on postural dysfunction: Recommendations for prevention, diagnosis and therapy. J. Biol. Regul. Homeost. Agents 2021, 35, 441-456. 
39. Sakaguchi, K.; Mehta, N.R.; Abdallah, E.F.; Forgione, A.G.; Hirayama, H.; Kawasaki, T.; Yokoyama, A. Examination of the relationship between mandibular position and body posture. Cranio 2007, 25, 237-249. [CrossRef]

40. Takahashi, Y. A study on the influence of occlusal position on posture control using the head sway as an index. Nihon Univ. Dent. J. 2001, 75, 281-289.

41. Bracco, P.; Deregibus, A.; Piscetta, R. Effects of different jaw relations on postural stability in human subjects. Neurosci. Lett. 2004 356, 228-230. [CrossRef] [PubMed]

42. Moscagiuri, F.; Caroccia, F.; Lopes, C.; Di Carlo, B.; Di Maria, E.; Festa, F.; D'Attilio, M. Evaluation of Articular Eminence Inclination in Normo-Divergent Subjects with Different Skeletal Classes through CBCT. Int. J. Environ. Res. Public Health 2021, 18, 5992. [CrossRef]

43. Miralles, R.; Palazzi, C.; Ormeño, G.; Giannini, R.; Verdugo, F.; Valenzuela, S.; Santander, H. Body position effects on EMG activity of sternocleidomastoid and masseter muscles in healthy subjects. Cranio 1998, 16, 90-99. [CrossRef] [PubMed]

44. Zhang, C.; Wu, J.Y.; Deng, D.L.; He, B.Y.; Tao, Y.; Niu, Y.M.; Deng, M.H. Efficacy of splint therapy for the management of temporomandibular disorders: A meta-analysis. Oncotarget 2016, 7, 84043-84053. [CrossRef] [PubMed]

45. Milani, R.S.; De Perière, D.D.; Lapeyre, L.; Pourreyron, L. Relationship between dental occlusion and posture. Cranio 2000, 18, 127-134. [CrossRef] 